\title{
Normocytic Normochromic Anemia Revealed an Early Onset Hashimoto's Hypothyroidism in an Infant: A Case Report
}

\author{
Manal Mustafa Khadora ${ }^{a}$ Maysa Saleh ${ }^{a}$ Rawah Idres $^{a}$ Sura Ahmed Al-Doory ${ }^{b}$ \\ Mahmoud Ahmed Radaideh ${ }^{b}$ \\ aDepartment of Pediatric Endocrinology, Latifa Women's and Children's Hospital, Dubai, UAE; \\ bepartment of Pediatric Hematology, Latifa Women's and Children's Hospital, Dubai, UAE
}

\section{Keywords}

Hashimoto's thyroiditis - Acquired hypothyroidism .

Autoimmune thyroiditis · Erythroblastopenia · Normocytic normochromic anemia

\begin{abstract}
Autoimmune thyroiditis is very rare etiology of primary hypothyroidism in infancy. Hypothyroidism has a wide range of clinical presentation, from subclinical hypothyroidism to overt type. It is unclear what pathological mechanisms connect thyroid function and erythropoiesis or how thyroid disease can contribute to anemia. We report a 12-month-old infant who presented with anemia associated with early onset of overt autoimmune thyroiditis. The peculiarity of our case enables us to draw attention of physician to consider acquired hypothyroidism in the differential diagnosis of unexplained anemia even if the neonatal screening is normal and congenital hypothyroidism is a remote possibility.
\end{abstract}

(c) 2021 The Author(s).

Published by S. Karger AG, Basel

\section{Introduction}

In children, the commonest cause of thyroid disorder is primary hypothyroidism. Autoimmune thyroiditis is considered the most common cause of acquired hypothy- roidism in children (also known as chronic lymphocytic or Hashimoto thyroiditis) [1]. Primary acquired hypothyroidism caused by autoimmune thyroiditis is extremely uncommon in children under the age of 3 [2]. Hypothyroidism can present with various signs and symptoms that might be subclinical hypothyroidism or overt form. Thyroid hormones promote development of the erythroid colonies, either directly or indirectly via erythropoietin. Anemia, which could be macrocytic, normocytic, or hypochromic-microcytic, is expected in thyroid hormone deficiency. Restoration of thyroid function, with specific therapy, is often required for complete anemia correction [3]. We describe a 12-month-old infant with acquired autoimmune thyroiditis, manifested early in his life, and presented with unexplained normocytic normochromic anemia.

\section{Case Presentation}

The twelve-month-old infant presented to the pediatric hematology clinic with unexplained normochromic normocytic anemia. At the age of 2 months, the child was admitted with fever, his full blood count showed low hemoglobin (HB) $8.7 \mathrm{mg} / \mathrm{dL}$ (normal range $[\mathrm{N}] 11.1-14.1 \mathrm{~g} / \mathrm{dL}$ ), low mean corpuscular volume (MCV) $76.7 \mathrm{fL}(\mathrm{N} ; 87.0-103.0 \mathrm{fL})$, and low mean corpuscular HB $24.5 \mathrm{pg}$ $(\mathrm{N} ; 27.0-33.0 \mathrm{pg})$. This result was attributed to physiologic anemia of infancy. At the age of 7 months, he was readmitted with RSV pneumonia, $\mathrm{HB}$ was $8.7 \mathrm{mg} / \mathrm{dL}, \mathrm{MCV}: 71.0 \mathrm{fL}(\mathrm{N})$, and mean karger@karger.com www.karger.com/dmj

Karger $\stackrel{\text { ' }}{=}$

BOPEN ACCESS
(C) 2021 The Author(s)

Published by S. Karger AG, Basel

This is an Open Access article licensed under the Creative Commons Attribution-NonCommercial-4.0 International License (CC BY-NC) (http://www.karger.com/Services/OpenAccessLicense), applicable to the online version of the article only. Usage and distribution for commercial purposes requires written permission.
Correspondence to:

Sura Ahmed Al-Doory, saaldoory@ dha.gov.ae 


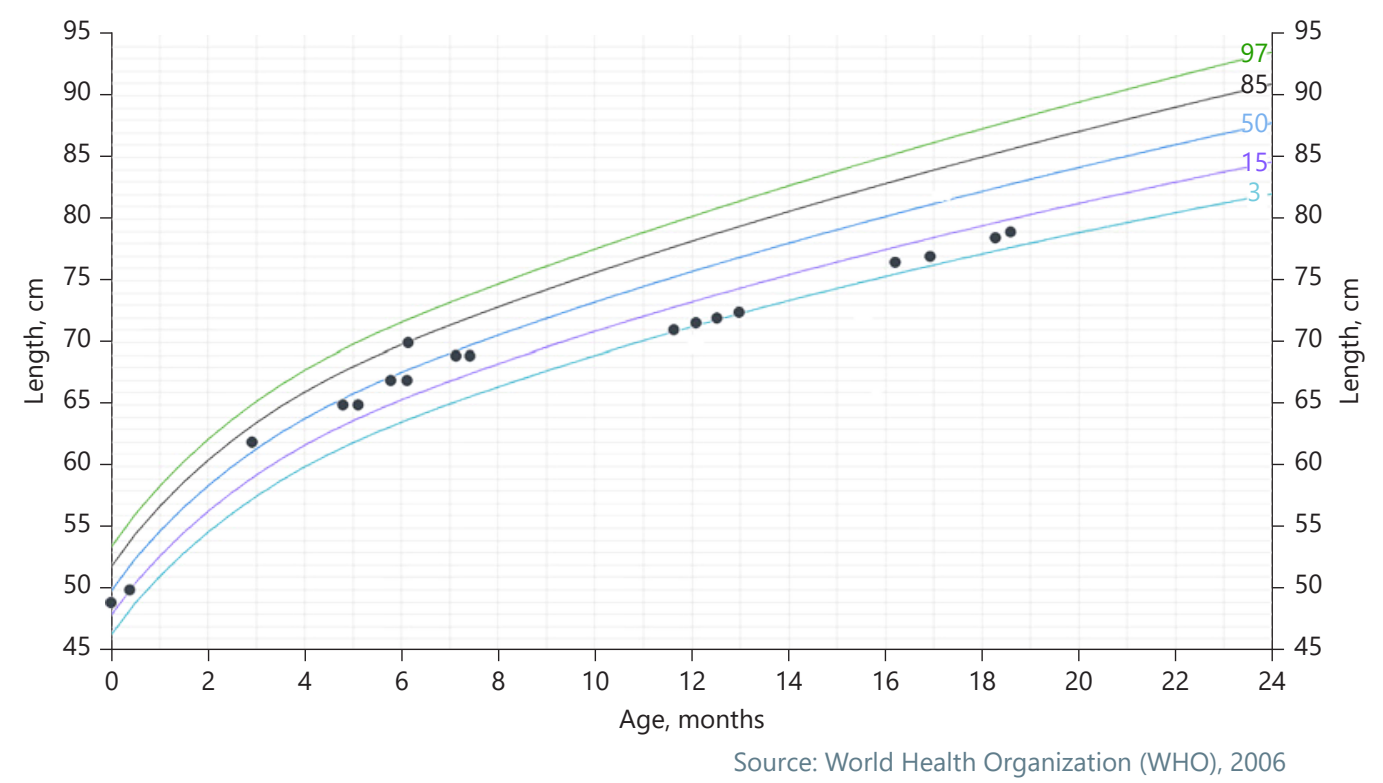

Fig. 1. Length chart.

corpuscular hemoglobin: $22.7 \mathrm{pg}$ (low). Repeated full blood count showed a further decline of the HB level to $7.9 \mathrm{mg} / \mathrm{dL}$. Red blood cell count was within normal limits: 3.83 and $3.56 \times 10^{6} / \mu \mathrm{L}$, respectively $\left(\mathrm{N} ; 3.10-4.3010^{6} / \mu \mathrm{L}\right)$. Platelet counts, as well as leukocyte count, were normal. Reticulocyte count was low: $0.3 \%$ (normal range $0.5-2.5 \%)$. Iron studies and quantitative G6PD levels were normal. Peripheral blood film was consistent with normocytic anemia with reduced bone marrow response to the anemia. The possibility of transient erythroblastopenia of childhood was raised. The child had torticollis; thus, he was referred to physiotherapy. He was discharged with HB: $9.1 \mathrm{mg} / \mathrm{dL}$. At the hematology clinic, 2 weeks later, as noted by the parents, the child was sleepy, dull-looking with no social interaction, poor concentration, and no eye contact; he was responding to his name. His developmental milestones were at an average of 9-10 months. By the age of 12 months, he stood without support but not yet walking, no pincer grasp, and not clapping hands but occasionally waves goodbye. He had constipation despite adequate water and fiber intake in his diet. On examination, he had normal growth parameters: weight at 10th centile and height reduced from the 36th centile to 3 rd centile over 4 months (Fig. 1). He was pale, with bilateral periorbital puffiness, protruded tongue, sleepy, less interactive, no goiter, and mild right-sided torticollis. The remainder of the examination was unremarkable. HB level decreased to $8.2 \mathrm{~g} / \mathrm{dL}$. Leukocyte and platelet count remained normal. Reticulocyte count slightly increased from $0.3 \%$ to $0.7 \%$. Iron studies were normal. HB electrophoresis was reported as normal. He was born at term by lower segment caesarian section, with a birth weight of $2.8 \mathrm{~kg}$, and had an uneventful antenatal and postnatal period. The neonatal screening, which included TSH, was normal. Parents are 1st cousins; he has 2 elder siblings with no known medical concerns, and his mother has acquired hypothyroidism on thyroxine treatment. Paternal aunt and maternal grandmother have primary hypothyroidism; they are on treatment with thyroxine, no family history of known blood disorders. Hypothyroidism was clinically suspected, so thyroid function was sent. The report favored severe hypothyroidism with a very high TSH level: 516.4 $\mu \mathrm{IU} / \mathrm{mL}$ (normal range: 0.9-6.5 $\mu \mathrm{IU} / \mathrm{mL}$ ) and low Free T4: 0.4 $\mathrm{pmol} / \mathrm{L}$ (normal range 12.0-23.0 pmol/L). It is worth noting that the child's neonatal screening for TSH was normal, and TSH at age of 1 week was normal: $7.860 \mu \mathrm{IU} / \mathrm{mL}(\mathrm{N} ; 1.4-8.8 \mu \mathrm{IU} / \mathrm{mL})$ (Fig. 2). The child was referred to a pediatric endocrinology clinic. The diagnosis of severe acquired hypothyroidism was established, and L-Thyroxine $37.5 \mu \mathrm{g}$ alternating with $50 \mu \mathrm{g}$ orally daily was initiated. Thyroid antibodies and thyroid ultrasound scan were requested, and he was scheduled for follow-up after 2 weeks. Thyroid USS reported normal position and shape of the thyroid gland. Antithyroid peroxidase level was $213.0 \mathrm{IU} / \mathrm{mL}(N<34 \mathrm{IU} /$ $\mathrm{mL})$, and anti-thyroglobulin antibody level was $163.0 \mathrm{IU} / \mathrm{mL}(N$ $<115 \mathrm{IU} / \mathrm{mL}$ ) significantly high, supporting the diagnosis of Hashimoto's hypothyroidism. Four weeks later, a repeated thyroid function test revealed TSH $0.8 \mu \mathrm{IU} / \mathrm{mL}$ and Free T4 was 44.9 $\mathrm{pmol} / \mathrm{L}$. Hence, the thyroxine dose was adjusted to $37.5 \mu \mathrm{g}$ orally daily. After another 4 weeks, repeated TSH was $0.5 \mu \mathrm{IU} / \mathrm{mL}$ and Free T4 20 pmol/L. CBC showed resolving normocytic normochromic anemia with a HB level of $10.2 \mathrm{~g} / \mathrm{dL}$. He was continued on thyroxine $37.5 \mu \mathrm{g}$ PO OD and advised regular follow-up. Six months later, his TSH normalized to $6.0 \mu \mathrm{IU} / \mathrm{mL}$, Free T4: 17.6 $\mathrm{pmol} / \mathrm{L}$, and his $\mathrm{HB}$ was $10.1 \mathrm{~g} / \mathrm{dL}$. In view of the right torticollis, orthopedic consultation was obtained, and the family was reassured. The ophthalmologist assessed the child and diagnosed him with horizontal nystagmus, astigmatism, plus myopia of both eyes. He continued to receive multidisciplinary follow-up with the pediatric hematology, endocrinology, and ophthalmology teams. 
Fig. 2. Laboratory studies of the child.

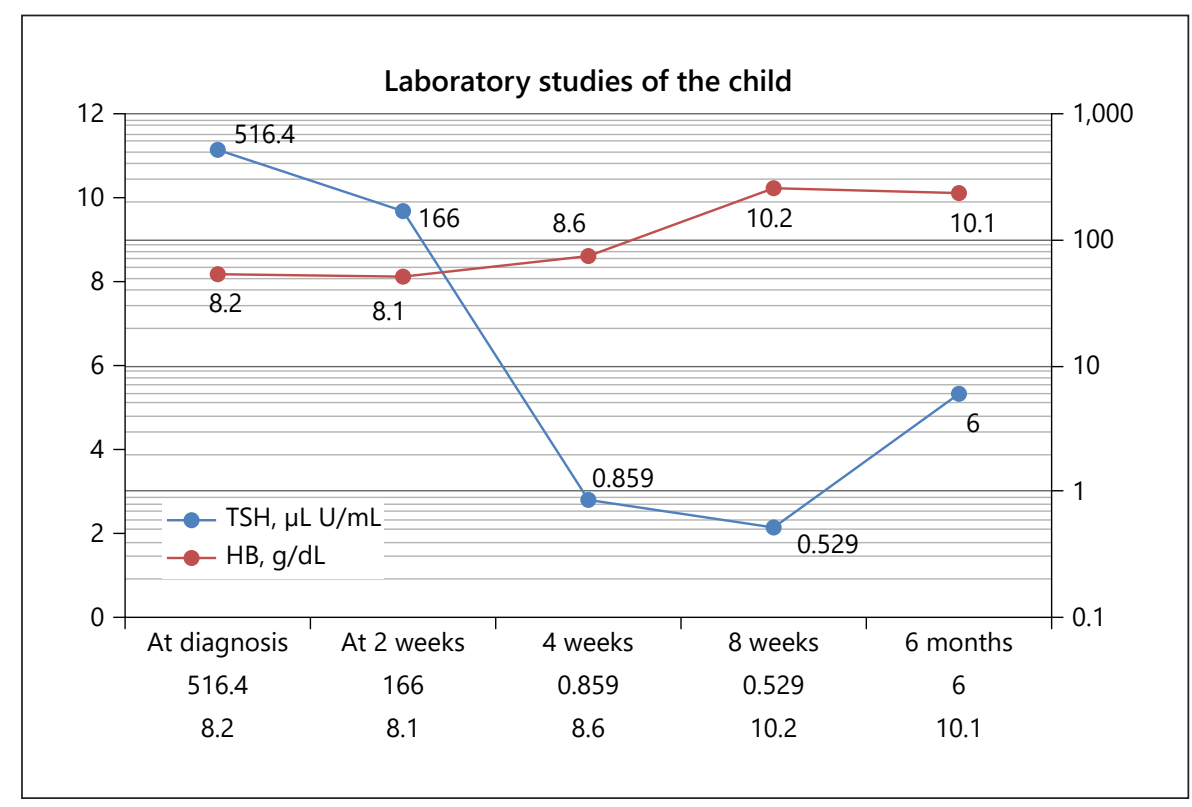

During his regular follow-up, at age of 18 months, the child was more alert and interactive, his facial expression normalized, and he was able to walk supported. His height increased to the 25th centile.

\section{Discussion}

Autoimmune thyroiditis, known as chronic lymphocytic or Hashimoto thyroiditis, is the commonest cause of pediatric-acquired hypothyroidism [1], which is rarely presented under 3 years of age [2]. Hypothyroidism and anemia also cause nonspecific signs of disease, such as exhaustion, with a detrimental effect on one's quality of life. Anemia and hypothyroidism coexistence is not only difficult to diagnose, but can also indicate a causal association between thyroid disease and anemia [3]. Indeed, there are links between thyroid disease and anemia, which have been previously documented in experimental animal studies [4]. On the other hand, human data regarding the relationship between hematologic disorders and thyroid are limited. Anemia was frequently observed in adult patients with hypothyroidism. The nature of the anemia noted in adult patients was quite variable $[5,6]$. The incidence of anemia in adult patients associated with hypothyroidism is reported to be between $21 \%$ and $100 \%$ [5, 6]. Adult hypothyroid patients were found to have a high rate of anemia. The type of anemia encountered by these patients has been very varied $[5,6]$. Researchers discov- ered red cell defects and a decreased proliferative capacity of hematopoietic progenitor cells in patients with hyperthyroidism and hypothyroidism [7]. Currently, it is still unclear what pathological mechanisms connect thyroid function and erythropoiesis or how thyroid disease can contribute to anemia. Low thyroid function may be related to anemia through deficits in development of healthy erythrocytes in both subclinical and overt hypothyroidism. The mechanisms by which thyroid hormones and TSH can cause anemia are not completely understood [8]; T3, T4, and TSH could play a part in erythropoiesis [9].

Moreover, T3 and T4 are involved in control of hematopoiesis by affecting the proliferative ability of erythroid precursors [10]. T4 was found to facilitate the initiation and completion of HB protein chain synthesis and promote red blood cells' production [11]. Furthermore, thyroid hormones could influence iron transport and consumption. TSH might affect hematopoiesis by binding to a functional TSH receptor found in erythrocytes and some extra-thyroidal tissues [7]. Moreover, iron deficien$c y$, the most common cause of anemia, could reduce thyroid peroxidase activity, an iron-containing enzyme involved in thyroid function [12].

Chu et al. [13] examined 17 children and adolescents (excluding neonates) with hypothyroidism. Anemia was observed in 11 patients (65\%). The red blood cells' MCV was either macrocytic or normocytic. The serum thyroxine level did not correlate with HB. Anemia was observed 
only in patients whose heights were below 3rd percentile, but they failed to have a similar correction to their weights. Patients who had anemia secondary to hypothyroidism responded well to thyroid hormone replacement therapy alone. In our case, detection of underlying etiology for normochromic normocytic anemia was challenging. The relationship between normochromic normocytic anemia and hypothyroidism in our patient was evident by excluding all other causes of normochromic normocytic anemia. Typical features of hypothyroidism (dullness, protruded tongue, delayed developmental milestones, and growth deceleration) and the dramatic improvement after starting L-Thyroxine therapy, with normalization of blood indices corresponding to normalization of thyroid function (Fig. 2), support the hypothesis that anemia and hypothyroidism were related.

The peculiarity of our case report was the early onset of autoimmune thyroiditis in our patient who was below 1 year of age, with severe hypothyroidism phenotype, associated with pallor and unexplained normochromic normocytic anemia. The age of presentation (below 1 year of age), the normal neonatal screening, and the normal serum level of repeated thyroid function at the age of 1 week made congenital hypothyroidism a remote possibility. Indeed, our patient showed growth deceleration, sleepy expression, dull-look, changes in the face habitus, delayed development milestones, social disinterest, and had constipation which raised the possibility of the diagnosis of hypothyroidism. Failure to relate the normochromic normocytic anemia to specific etiology apart from the possibility of transient erythroblastopenia of childhood and the rapid resolution of the anemia with improved thyroid function confirms the presence of anemia as sequelae to the acquired hypothyroidism.

We report this case to draw the attention of clinicians that despite regular neonatal screening for congenital hypothyroidism, extreme overt hypothyroidism due to autoimmune thyroiditis can develop early in life. Autoimmune thyroiditis was discovered in our patient early in his life, when thyroid hormones are essential for proper mental growth [14], necessitating close monitoring and potential cognitive evaluation to identify the outcome better and start appropriate interventions. Furthermore, we strongly recommend considering hypothyroidism in the differential diagnosis of cases of unexplained, persistent normochromic normocytic anemia. We believe that the association of disorders in the blood indices in cases of hypothyroidism might signal the severity of the condition.

\section{Conclusions}

While neonatal screening for congenital hypothyroidism is routine, extreme acquired hypothyroidism due to autoimmune thyroiditis may occur early in life, and clinicians should be aware of this possibility. Hypothyroidism can present in various ways, particularly with anemia, which can be the presenting symptom and the most prominent manifestation. Hypothyroidism can have a deceptive and multifaceted clinical appearance, especially with unexplained anemia. Hypothyroidism should be considered in the differential diagnosis of normocytic, normochromic anemia in infants who have a falloff in linear growth and present with normocytic, normochromic anemia of uncertain origin. Thyroxine replacement therapy alone can restore all clinical manifestations linked to hypothyroidism and anemia. Further studies are needed to determine the possible underlying mechanism of this association.

\section{Statement of Ethics}

Ethical approval was not required for this case report in accordance with the Dubai Health Authority Research Committee policies. Written and informed consent was obtained from the patient's parents for publishing the case report including accompanying images.

\section{Conflict of Interest Statement}

The authors have no conflicts of interest to declare.

\section{Funding Sources}

The authors have no funding sources to declare.

\section{Author Contributions}

M.M., M.S., and R.I. have composed the manuscript and obtained guardian consent. All remaining co-authors have contributed to critical review and editing of the report.

\section{Data Availability Statement}

All data generated or analyzed during this case report are included in this article. Further inquiries can be directed to the corresponding author. 


\section{References}

1 Rallison ML, Dobyns BM, Keating FR, Rall JE, Tyler FH. Occurrence and natural history of chronic lymphocytic thyroiditis in childhood. J Pediatr. 1975;86(5):675-82.

2 Mittnacht J, Schmidt F, Ebinger F, Bettendorf M. Unusual clinical presentation of primary hypothyroidism in a very young infant caused by autoimmune thyroiditis: case report and update of the literature. Eur J Pediatr. 2007 Aug;166(8):881-3.

3 Patel R, Jain A. Study of anemia in primary hypothyroidism. Thyroid Res Pract. 2017; 14(1):22-4.

4 Fein HG, Rivlin RS. Anemia in thyroid diseases. Med Clin North Am. 1975;59(5):113345.

5 Wintrobe MM. Anemias associated with endocrine disorders, the clinical hematology. 7th ed. Philadelphia: Lea \& Febiger; 1974. p. 709-16.
6 Tudhope GR, Wilson GM. Anemia and hypothyroidism, the thyroid and the blood. Spring field. Illinois: Charles C Thomas; 1969. p. 2436.

7 Kawa MP, Grymula K, Paczkowska E, Baskiewicz-Masiuk M, Dabkowska E, Koziolek M, et al. Clinical relevance of thyroid dysfunction in human haematopoiesis: biochemical and molecular studies. Eur J Endocrinol. 2010 Feb;162(2):295-305.

8 Maggio M, De Vita F, Fisichella A, Lauretani F, Ticinesi A, Ceresini G, et al. The role of the multiple hormonal dysregulation in the onset of "anemia of aging": focus on testosterone, IGF-1, and thyroid hormones. Int J Endocrinol. 2015;2015:292574.

9 Perrin MC, Blanchet JP, Mouchiroud G. Modulation of human and mouse erythropoiesis by thyroid hormone and retinoic acid: evidence for specific effects at different steps of the erythroid pathway. Hematol Cell Ther. 1997 Feb;39(1):19-26.
10 Golde DW, Bersch N, Chopra IJ, Cline MJ. Thyroid hormones stimulate erythropoiesis in vitro. Br J Haematol. 1977 Oct;37(2):173-7.

11 Fandrey J, Pagel H, Frede S, Wolff M, Jelkmann W. Thyroid hormones enhance hypoxia-induced erythropoietin production in vitro. Exp Hematol. 1994 Mar;22(3):272-7.

12 Khatiwada S, Gelal B, Baral N, Lamsal M. Association between iron status and thyroid function in Nepalese children. Thyroid Res. 2016;9(1):2.

13 Chu JY, Monteleone JA, Peden VH, Graviss ER, Vernava AM. Anemia in children and adolescents with hypothyroidism. Clin Pediatr. 1981 Nov;20(11):696-9.

14 Joergensen JV, Oerbeck B, Jebsen P, Heyerdahl S, Kase BF. Severe hypothyroidism due to atrophic thyroiditis from second year of life influenced developmental outcome. Acta Paediatr. 2005 Aug;94(8):1049-54. 